\title{
Assessment Of Afasia in Stroke Patients: Case Study
}

\author{
Dwi Febryanto, Retnaningsih, Fitria Handayani \\ Diponegoro University, Semarang, Indonesia \\ Corresponding author: dwifebryanto37@gmail.com
}

\begin{abstract}
Background: Aphasia is understood as difficulty in understanding or producing language caused by disorders involving the brain hemispheres. Early assessment of aphasia is very important to prevent the emergence of telegraphic speech styles, improve welfare, independence, social participation, quality of life, reduce length of stay and care costs, but there is little literature on this subject, especially in stroke patients.

Purpose: This study aimed to provide an overview of the assessment of aphasia in stroke patients.

Methods: The design of a case study involving 6 participants and data collection was carried out by conducting an assessment using the Language Aphasia Screening Test (LAST) instrument which was monitored for 3 days, including monitoring errors for naming images, monitoring mismatches repeating words and sentences, monitoring spontaneous pronunciation, monitoring image comprehension, monitoring comprehension of verbal instructions.

Results: A total of 6 ischemic stroke patients were found wrong in repeating words and sentences.

Conclusion: In aphasic stroke patients all language modalities are impaired, ranging from spontaneous speech, repetition, naming, language comprehension, reading and writing.
\end{abstract}

Keywords: Stroke phenomenon, Aphasia, Assessment 


\section{BACKGROUND}

The prevalence of stroke in Sri Lanka in 2015 was 104 per 1,000 population and in China in 2017 was 1,596 per 100,000 population (Chang, Gajasinghe, \& Arambepola, 2015; Wang et al., 2017). Stroke patients in Japan were 1,693 patients, 52, 5\% experienced aphasia, whereas the prevalence of stroke in Indonesia increased from 2013-2018, namely $7.0 \%$ to $10.9 \%$ (Kemenkes RI, 2014). Stroke sufferers who experience aphasia due to acute stroke are around 30\% (Kemenkes RI, 2014; Pinzon, 2010).

Both ischemic and hemorrhagic stroke patients who are treated, are often found to experience paralysis of the limbs, perot face, pelo, and even found aphasia. Aphasia is understood as difficulty in understanding or producing language caused by disorders involving the brain hemispheres. In patients with aphasia all impaired language modalities, ranging from spontaneous speech, repetition, naming, language comprehension, reading and writing (Lumbantobing, 2000), hysiological changes in aphasia are often found in stroke patients so that the problem of verbal communication disorders should be found in the CPPT Integrated Patient Development Record but, based on observations this problem is very rarely found. Nurses are important to assess stroke aphasia to detect and evaluate patient progress, because nurses often find signs of stroke aphasia patients in the form of speech disability, slowness, and difficulty expressing words so that communication is disrupted (Al-Khawaja, Wade, \& Collin, 1996; Poslawsky, Schuurmans, Lindeman, \& Hafsteinsdóttir, 2010) Nurses collect subjective and objective data and then establish nursing diagnoses of verbal communication disorders. (PPNI, 2016) Nurses can intervene in the form of providing support for treatment programs and decision making for care actions (Berthier, 2005; PPNI, 2016). On the other hand, nurses can carry out their advocacy functions to defend clients if patients do not get proper treatment.

The unavailability of a nurse-specific assessment tool for the assessment of stroke aphasia results in the absence of nurses' actions to conduct an aphasia assessment in stroke patients. Another factor of nurses who do not do aphasia assessments is the knowledge of nurses related to aphasia assessment. Nurses only know the signs and symptoms of aphasia such as speech difficulties experienced by patients, which when examined with instruments can provide good judgment. stroke patients who experience aphasia, they are not able to understand spoken language, difficulty coordinating thoughts, feelings and desires (Enderby, Wood, Wade, \& Hewer, 1986; Flamand-Roze et al., 2011) Severe stroke aphasia patients are characterized by no there is spontaneous language, however the patient may mention a few repetitive words but is unable to understand pronunciation (Enderby et al., 1986; Flamand-Roze et al., 2011) This can cause a psychological change in the patient's form of anxiety, stress and depression (Shehata, 2015)

Acute stroke aphasia patients have difficulty communicating, making them anxious because they cannot express their desires, hopes and complaints so well that they depend on the people closest to convey their desires and complaints. Aphasia strokes also have an impact on well-being, independence, social participation, quality of life and length of stay. Stroke patients with aphasia will experience an additional stay of an average of 1-2 weeks. The addition of the length of stay will increase the cost of care (Corallo et al., 2017)

Efforts to prevent the impact of aphasia due to stroke is to recognize aphasia as early as possible. Many instruments to assess aphasia due to stroke such as Boston Diagnostic Aphasia Examination (BDAE), Minnesota Test for Differential Diagnosis of Aphasia (MTTDDA), Functional Communication Profile (FCP). All of these tools have their own specifications, and their own scoring system. This measuring instrument takes between 30 minutes to 3 hours to detect aphasia (Erdodi \& Roth, 2017; Prins \& Maas, 2002) This 


\section{Journal Of Nursing Practice}

http://thejnp.org

ISSN: 2614-3488 (print); 2614-3496 (online)

Vol.3 No.2. April 2020. Page.210-219

measurement tool is difficult to do in patients who do not tolerate a long time. Questions used in the "understanding" sub-test produce answers in the form of "yes and no" so that patients can answer them only by tilting their heads which can lead to bias (Erdodi \& Roth, 2017; Prins \& Maas, 2002) Screening tools such as the Mobile Aphasia Screening Test (MAST), Sheffield Screening Test (SST) and Screeling are screening tools for detection of acute stroke aphasia with a time of 3-15 minutes and onset of attack 1-127 days (El Hachioui et al., 2017) The measuring devices without sub-tests that require "yes and no" answers, but even without sub-tests that require yes and no answers, the screening tool is only specifically done by a therapist or specialist doctor while other health workers cannot use this (El Hachioui et al., 2017; Erdodi \& Roth, 2017)

Assessment tools for the assessment of stroke aphasia use the Language Screening Test (LAST) in the form of an image stimulus using instructions and a hint card without a "yes and no" question. This assessment tool is more detailed, easy to use, fast and does not involve writing sub-tests (El Hachioui et al., 2017). LAST is a measuring tool developed for health professionals in detecting stroke aphasia (Flamand-Roze et al., 2011). LAST can assess as a whole because it has 5 clinical indicators namely naming images, syllable repetition, sub spontaneous speaking tests, understanding images and verbal commands, without writing subtes. Previous measuring instruments are very time-consuming, existing instruments are also still very high from the risk of bias because they involve writing subtests and are difficult to interpret by nurses while a brief, low-bias and easily interpretable assessment is needed (Flamand-Roze et al., 2011) LAST is the only fastest tool in detecting aphasia with only 2-3 minutes, low bias and simple and easy to interpret (Flamand-Roze et al., 2011; Flowers, Flamand-roze, Denier, \& Roze, 2015; KoenigBruhin et al., 2016) LAST has also been validated in stroke patients. LAST has a good rating for knowing patients with aphasia. The LAST assessment instrument is a good aphasia screening and evaluation tool, has high sensitivity, and is an accurate diagnostic instrument with high specificity for aphasia assessment in stroke patients. Seeing the importance of knowing aphasia early, it is necessary to do an assessment using easy and efficient tools.

\section{OBJECTIVE}

This study aimed to provide an overview of the assessment of aphasia in stroke patients based on assessment using the LAST instrument

\section{METHODS}

Participants in this study involved 6 patients who had a stroke. Participants were selected according to inclusion and exclusion criteria. The inclusion criteria in this study were men and women aged 40-80 years, declared ischemic or hemorrhagic stroke based on CT scan, Indonesian language. Exclusion Criteria are patients experiencing decreased consciousness, illiteracy, blindness and deafness. The process of data collection is done by first doing licensing by giving informed consent to the family or patient, conducting an aphasia assessment with LAST measuring instruments that have been translated and monitored for 3 days. The method used is a case study. 
Journal Of Nursing Practice

http://thejnp.org

ISSN: 2614-3488 (print); 2614-3496 (online)

Vol.3 No.2. April 2020. Page.210-219

RESULTS

Table 1. Demographic Data on Case Studies of Patients with Stroke Aphasia

\begin{tabular}{cccccl}
\hline NO & Patient & $\begin{array}{c}\text { Age } \\
\text { (years) }\end{array}$ & Gender & $\begin{array}{c}\text { Hospitalization } \\
\text { day }\end{array}$ & \multicolumn{1}{c}{ CT Scan Results } \\
\hline 1. & Mr. F & 49 & Male & 3 & Infarction of the left insula \\
\hline 2. & Mrs. R & 60 & Female & 2 & $\begin{array}{l}\text { Intracerebral hemorrhage in the basal ganglia to } \\
\text { the left corona radiata }\end{array}$ \\
\hline 3. & Mr.N & 50 & Male & 2 & $\begin{array}{l}\text { Intraserebral hemorrhage in the Caudatus } \\
\text { nucleus to the left corona radiata }\end{array}$ \\
\hline 4. & Mrs. P & 70 & Female & 2 & lunarar infarction of the right external capsule \\
\hline 5. & Mr. T & 50 & Male & 1 & lunarar infarction in the right lentiform nucleus \\
\hline 6. & Mr. S & 62 & Male & 2 & Lakunar infarction in the left lentiform nucleus \\
\hline
\end{tabular}

Mr. F, 49 years old, was admitted to the treatment room on August 26, 2019. The patient was assessed for aphasia on the 3rd day care in the ward with a medical diagnosis of Non-Hemorrhagic Stroke + Hemiparese Dextra. With the results of a CT scan of the head without contrast, namely infarction in the left insula. At present the patient has weak right limbs. Composmentis patient awareness, GCS E4M5V5. Examination of Vital Signs Temperature 36.5oC, pulse 105 x / minute, Blood Pressure 190/119 mmHg, RR 20x / minute. The patient has a history of hypertension since 2012 and rarely controls. In the family of the father and sister the patient also suffered the same stroke suffered by the patient at this time. On a physical examination the focus is obtained data that the client's face is not symmetrical, perot mouth.

Aphasia studies were performed on patients on the third day of treatment, aphasia scores using the LAST instrument obtained 13, the patient experienced a pronunciation error on the mathematics word sub-test repetition and the postman brought my neighbor's letter. While the naming test, spontaneous pronunciation, understanding of images and verbal instructions can be done appropriately.

On the fourth day, a review was conducted and showed that the aphasia score was still the same at 13 , while on the 5th day the patient was able to repeat the words and sentences correctly so that the LAST score was 15.

Mrs. R aged 60 years entered on August 25, 2019. The assessment was carried out on the second day of treatment at Bagsal with a medical diagnosis of intracerebral hemorrhage. The assessment was carried out and found that the patient complained of weak right limbs and difficulty speaking, awareness of patient Composmentis, GCS E4M5V5. The patient has a history of hypertension. The patient was put on a 20 drops per minute RL infusion in the left hand. On a physical examination focused on the data that, perot mouth, pelo pronunciation, patients can speak slowly, extremities of the right hand and foot are weak. CT scan results of intracerebral hemorrhage in the basal ganglia to the left corona radiata.

On the first day the LAST score is 10, the client gets a speech therapy program, and the second day the LAST score is 11 , the client can name the picture, the repetition subtest is wrong, the spontaneous speech test is correct, the picture understanding test is still wrong, the verbal instruction test can do correctly.

Fourth and fifth day evaluations in patients found patients still complained of difficulty moving the right limb, TD 145/90 $\mathrm{mmHg}$, right limb muscle strength 4: 4, and speech still pelo with LAST score 14 . The physiotherapy and speech therapy process had actually been carried out, because the patient has weakness in the right limb and there is a speech impediment. Evaluation on diagnoses of verbal communication disorders, 


\section{Journal Of Nursing Practice}

http://thejnp.org

ISSN: 2614-3488 (print); 2614-3496 (online)

Vol.3 No.2. April 2020. Page.210-219

measured using LAST instruments. Beginning of the study where it was found that there were errors in the pronunciation of mathematical words, the patient was immediately motivated to practice saying mathematics. The patient gets word pronunciation exercises like mathematics, the postman brings my neighbor's letter, always during the shift and every time the nurse visits the patient. The third day after the patient got pronunciation practice, the patient was not able to correctly answer the word mathematics and the postman brought my neighbor's letter. Motor speech training is indeed able to restore the patient's speech style and help patients recognize the treatment environment. Providing speach motor exercises at least once per shift can enable patients to complete the word repetition sub test well. Treatment continues until the patient returns and requires recontrol. Finally the patient is allowed to go home and control a week after.

Mr. N, 50 years old. Patients entered the treatment room on September 8, 2019. The assessment was carried out on the second day with the results of a CT scan, namely Intracerebral Bleeding in the Coedetus nucleus to the left corona radiata. client's main complaint based on assessment of the family is a headache with additional complaints namely difficulty speaking and weakness in the right limb. Client's Blood Pressure is $180 / 107 \mathrm{mmHg}$. The client has no history of hypertension but has a history of asthma. At present the client is just silent and not talking. The therapy received by the client on September 9, 2019 is Infusion of R1 20 drops per minute, Citicolin 2x500 mg, tranexamic acid 3x1 gram, ranitidine 3x1 ampoule, mannitol 4x125 cc, Amlodipin 1x20 mg, Clonidin $2 \times 0.150 \mathrm{mg}$. LAST assessment on the first day is obtained LAST score obtained 0. Clients can not speak at all. Clients get a speech therapy program. On the second day the LAST Score is still obtained 0 . The client is completely unable to speak. Speech practice uses the pictures contained in the LAST instrument. The client cannot say a word, only bow his head. On the third day the evaluation was made again after speech therapy, LAST Score obtained 0 . Clients can make sounds without meaningful words. The client cannot say a word, only bow his head.

Mrs. P, 70 years old, for indications of a non-hemorrhagic stroke on September 14, 2019. The patient was assessed for aphasia on the second day of care. the client's main complaints are weakness in the right limbs, difficulty speaking and headaches. Clients have a history of hypertension, and rarely do routine control. Radiological examination results are lacurer infarction on the right external capsule. The therapy received by the client on September 16, 2019 was Infusion of Rl 20 drops per minute + Vitamin B12, Piracetam 4x3 gr, Citicolin 2x500 mg, ranitidine 2x1 ampoule. On the first day of the LAST assessment it is found that the client can only understand the designated image, with a LAST score of 5. The client gets a speech therapy program. On the second day of development after speech therapy, the client can only say yes, make a sound without meaningful. The client cannot name the picture, the client cannot repeat words and sentences, the client can count 1-10, the client can understand the picture and follow verbal instructions. On day 3 development, the patient has not been able to name the picture, repeat the word, but can count even though the pronunciation is still wrong, can understand the picture and perform verbal instructions. LAST Value 7.

Mr. T 50 years old, Patient entered the treatment room on September 19, 2019. The assessment was carried out on the first day of treatment, the client entered with complaints of pelo speech and weakness of the right limb. The client has no history of hypertension and cholesterol. Radiological examination results are right lentiform nucleus lacurer infarction. The therapy received by the client on September 16, 2019 was R1 20 drops per minute, Piracetam 4x3 gr, Citicolin 2x500 mg, ranitidin 2x1 ampoule, Aspilet 1x1 tablet, 


\section{Journal Of Nursing Practice}

http://thejnp.org

ISSN: 2614-3488 (print); 2614-3496 (online)

Vol.3 No.2. April 2020. Page.210-219

Extra injection of Ondansentron $4 \mathrm{mg}$, then $2 \times 1$. On the development of the first day LAST Score was found 13. Clients can name pictures correctly, there are pronunciation errors when repeating words and sentences, clients can say spontaneous words, clients can understand images and perform verbal instructions correctly. The development of day 2 and 3 clients can repeat mathematical words correctly, and clients can repeat sentences from the postman carrying a letter to my neighbor appropriately. LAST score of 15 .

Mr. 62 years old, Patient enters the treatment room on October 1, 2019. The assessment is carried out on the second day of treatment, the client enters with complaints of pelo speech and weakness of the right limb. The client has a history of hypertension and is not routine control. The results of radiological examination are lunarar infarction in the left lentiform nucleus. Therapy received by clients on October 1 st 2019, namely Infusion of Rl 20 drops per minute, Piracetam 4x3 gr, Citicolin 2x500 mg, ranitidine 1 ampoule, Amlodipin $10 \mathrm{mg}$. On the development of the first day LAST Score was found 13. Clients can name pictures correctly, there are pronunciation errors when repeating words and sentences, clients can say spontaneous words, clients can understand images and perform verbal instructions correctly. The development of the second day the client is still the same as repeating words and sentences and the third client can repeat the mathematical word correctly, and the client can repeat the postman sent a letter to my neighbor correctly LAST score of 15.

\section{DISCUSSION}

The results of the case study found that six patients experienced aphasia on the first day to the third post-stroke day in the treatment room. This is in agreement with research conducted by Flamand Roze which states that aphasia in post-stroke usually occurs in the acute phase, which is in the range 1-5 days after the attack (Flamand-Roze et al., 2011). Besides stroke aphasia can also recover spontaneously with a little intervention needed to rehabilitate. All participants with post-stroke both iscemic and hemorrhagic were confirmed by CT scan. The cause of aphasia due to stroke both ischemic and hemorrhagic which causes nerve palsy hypoglossal brain in the temporal fronto lobe of the brain (Pinzon, 2010). Stroke aphasia patients are unable to understand oral language, difficulty coordinating thoughts, feelings and desires (Lumbantobing, 2000). Aphasia patients Severe strokes are characterized by no more spontaneous language. Patients can mention several repeated words but are unable to understand pronunciation (Lumbantobing, 2000). in addition, stroke risk factors that cannot be changed are age, gender, family history and previous stroke history. The older a person is, the more susceptible to stroke. This is due to the higher incidence of stroke risk factors such as hypertension in men. The Venketasubramanian et al (2005) study of 14906 subjects in Singapore showed that the prevalence of stroke over 65 years was $7.67 \%$, and it was significantly higher in the <65 years age group at $4.05 \%$. The prevalence of stroke in men is 1.5 times higher than in women (4.53\% vs $2.91 \%)$. In addition, according to Prof. Lumbantobing said that age is a significant factor in evaluating aphasia. Normal people under 69 years old will be able to name 20 animals with a standard deviation of 4.5 . This ability decreased to 17 in the $70 \mathrm{~s}$ and to 15.5 in the 80s. If the score is less than 13 in normal people under 70 years, it is necessary to suspect interference in the verbal fluency (Lumbantobing, 2000)

Spontaneous recovery of acute stroke aphasia occurs within 1-3 months. This is supported by research conducted by Culton in Marshall and Campbell (2013) who investigated stroke patients with an onset of less than 30 days tested with a number of measures (Campbell \& Marshall, n.d.) El Hachioui in Marshall and Campbell (2013) also reported 147 aphasia 


\section{Journal Of Nursing Practice}

http://thejnp.org

ISSN: 2614-3488 (print); 2614-3496 (online)

Vol.3 No.2. April 2020. Page.210-219

patients at $<6$ weeks, 3 months, 6 months and 1 year found patterns of recovery in phonology, syntax and semantics. Whereas those receiving semantic and syntax aspects of screeling increased up to 6 weeks, and phonology improved up to 3 months (Campbell \& Marshall, n.d.) The largest prospective study of spontaneous recovery is found in Sweden. Paderson, et al in Marshall and Campbell (2013) reported that 330 stroke patients were present at admission, hospitalization and outpatient care for up to 6 months. The results showed that language function became stationary at $84 \%$ at 2 weeks after onset and $95 \%$ of patients at 6 weeks after onset (Campbell \& Marshall, 2013)

The largest prospective study of spontaneous recovery is found in Sweden. Paderson, et al in Marshall and Campbell (2013) reported that 330 stroke patients were present at admission, hospitalization and outpatient care for up to 6 months. The results showed that language function became stationary at $84 \%$ at 2 weeks after onset and $95 \%$ of patients at 6 weeks after onset (Campbell \& Marshall, 2013)

Two participants experienced errors in naming the images. Errors in naming images are also closely related to lesions in brain regions. lesions in the temporal lobe in the medial and inferior gyrus areas (angular gyrus). Patient talks are generally smooth, it's hard to find the right words for certain objects. This aphasia is known as anomic aphasia (difficulty in naming an object). Patients can understand written and verbal language, comprehension and normal repetition (Dronkers, 2010)

The results of the assessment of aphasia with LAST showed that 6 participants experienced mismatches and errors in repeating words and sentences. The patient mispronounced a mathematical word and the postman sent with my neighbor's letter.

Studies show stroke aphasia patients will have trouble repeating words or sentences. This relates to the location of the lesion, if the lesion is at the motor talk center in area 44 and the surrounding area. The repetition of a single word is still good even if done with a variety of efforts. Repetition of bad sentences, especially sentences containing short words (such as: if, not, and, or, but (Dronkers, 2010; Yusiana \& Suwardianto, 2014; Suwardianto \& Richard, 2017; Weiner, 2000) Lesions in the posterior temporal gyrus of the auditory association cortex (area 22) or gyrus supramarginalis (area 40). Symptoms are that language comprehension will be interrupted and lose the ability to repeat the words spoken by others. Spontaneous speech goes smoothly with fast rhythm and normal articulation. Submission of information is bad because of circumcollution, the use of words that are meaningless, and incorrect. Patients use the wrong words and sounds, and are unable to understand writing, verbal language and naming a bad objec (Dronkers, 2010; Silbernagl \& Lang, 2007; Weiner, 2001)

If the lesion is in the temporal or parietal region which is related to the arctic fascicles which connect the Wernicke (sensory) area to the Broca (motoric) area. The conversation is smooth even though sometimes paraphrasing and understanding the language is good. Patients can understand a speech or written sentence that contains short words, but the ability to repeat words is very disturbed (Dronkers, 2010; Silbernagl \& Lang, 2007; Suwardianto, 2018; Suwardianto \& Rimawati, 2018; Weiner, 2000) Studies show normal people are generally able to repeat sentences that contain 19 syllables. Generally aphasia patients with impaired repeat ability have pathological abnormalities involving the peri-Sylvian region. If the ability to repeat is maintained, the Sylvian periarea is free from pathological abnormalities (Lumbantobing, 2000)

Repetition is often ignored in aphasia tests because it is not considered a function of natural language. Repetition tests have a significant theoretical and practical 
contribution to the analysis of aphasic disorders. Repetition is important to distinguish between conduction aphasia and transcortical aphasia (Kertesz, 2007)

The results of the assessment of stroke aphasia with LAST found that 2 participants experienced spontaneous pronunciation disruption. Studies show that extensive infarction in the area of vascularity of the cerebral artery often occurs in the occlusion of the left internal carotid artery or the base of the left cerebral artery. Hemiparesis is evident, accompanied by the inability of sufferers in terms of spontaneous speech and understanding of impaired language (Dronkers, 2010; Silbernagl \& Lang, 2007; Weiner, 2000)

The results of the assessment of aphasia with LAST found that 2 participants did not understand the instructed picture. Studies suggest that the ability of aphasia patients to understand is often difficult to assess. Simple examination that exists to assess the ability of understanding only gives a rough idea of the disorder and its severity, because the anatomical correlation with comprehension is complex (Lumbantobing, 2000) Visuals seen by clients are then translated by the brain specifically the occipital lobe region. The largest part of the cortex which is located medially in the primary zone is where visual stimulation is in charge of receiving stimulation from the contralateral visual field of both eyes. Visual language symbols are accepted as impulses in the primary center of the second occipital lobe of the hemisphere. Information is then forwarded to the visual association area, where the recognition and identification of language symbols occur. The area of visual association that handles language has two paths. First the information from the dominant visual association area goes directly to the word identification area. In the second path, information from the non-dominant area of visual association crosses into the dominant hemisphere through the corpus colosum. Information relating to object naming comes from both areas of visual association to the dominant hemisphere word recognition area. At this time the area of impulse recognition associated with naming objects enters the language system and is transmitted to the Wernicke area (Dronkers, 2010; Lumbantobing, 2000; Weiner, 2000) The association area is located around the primary cortex. If there is damage in this area, an image can be seen, but not recognized (there is visual agnosia or loss of ability to recognize objects, colors, people, sounds, shapes or smells even though the senses are uninterrupted) (Prins \& Maas, 2002; Silbernagl \& Lang, 2007)

The results of the assessment of aphasia with LAST found that 1 participant could not do verbal instructions correctly. Studies show that verbal instructions given can fail in patients with motor disorders, even though their understanding is good (Lumbantobing, 2000)

\section{CONCLUSION}

Aphasia phenomena can occur in stroke patients in the treatment room. Aphasia phenomena in stroke patients in the treatment room include the time of the stroke of aphasia after the attack, monitoring the client's ability to name images, repetition of words and sentences, speaking spontaneously, understanding images, understanding verbal instructions given to patients. The phenomenon that appears can be made a priority for nursing care for nurses after conducting an aphasia assessment with LAST.

LAST assessment is one of the aphasia studies that can be done by nurses. This tool can monitor the symptoms of aphasia. Monitoring is important to find out the immediate condition of aphasia in patients to make prevention or provide appropriate measures. Nursing actions that can be given to patients include support for treatment programs and decision making for care actions. 


\section{Journal Of Nursing Practice}

http://thejnp.org

ISSN: 2614-3488 (print); 2614-3496 (online)

Vol.3 No.2. April 2020. Page.210-219

\section{REFERENCES}

Al-Khawaja, I., Wade, D. T., \& Collin, C. F. (1996). Bedside screening for aphasia: a comparison of two methods. Journal of Neurology, 243(2), 201-204. https://doi.org/10.1007/BF02444015

Berthier, M. L. (2005). Poststroke aphasia. Drugs \& aging, 22(2), 163-182. https://doi.org/10.2165/00002512-200522020-00006

Chang, T., Gajasinghe, S., \& Arambepola, C. (2015). Prevalence of stroke and its risk factors in urban Sri Lanka: population-based study. Stroke, 46(10), 2965-2968. https://doi.org/10.1161/STROKEAHA.115.010203

Corallo, F., Bonanno, L., Buono, V. L., De Salvo, S., Rifici, C., Pollicino, P., ... \& Bramanti, A. (2017). Augmentative and alternative communication effects on quality of life in patients with locked-in syndrome and their caregivers. Journal of Stroke and Cerebrovascular Diseases, 26(9), 1929-1933. https://doi.org/10.1016/j.jstrokecerebrovasdis.2017.06.026

Dronkers, N., \& Baldo, J. V. (2010). Language: Aphasia. In Encyclopedia of Neuroscience (pp. 343-348). Elsevier Ltd. https://doi.org/10.1016/B978-008045046-9.01876-3

El Hachioui, H., Visch-Brink, E. G., de Lau, L. M., van de Sandt-Koenderman, M. W., Nouwens, F., Koudstaal, P. J., \& Dippel, D. W. (2017). Screening tests for aphasia in patients with stroke: a systematic review. Journal of neurology, 264(2), 211-220. https://doi.org/10.1007/s00415-016-8170-8

Enderby, P. M., Wood, V. A., Wade, D. T., \& Hewer, R. L. (1986). The Frenchay Aphasia Screening Test: a short, simple test for aphasia appropriate for non-specialists. International rehabilitation medicine, 8(4), 166-170. https://doi.org/10.3109/03790798709166209

Erdodi, L., \& Roth, R. (2017). Low scores on BDAE Complex Ideational Material are associated with invalid performance in adults without aphasia. Applied Neuropsychology: Adult, 24(3), 264-274. https://doi.org/10.1080/23279095.2016.1154856

Flamand-Roze, C., Falissard, B., Roze, E., Maintigneux, L., Beziz, J., Chacon, A., ... \& Denier, C. (2011). Validation of a new language screening tool for patients with acute stroke: the Language Screening Test (LAST). Stroke, 42(5), 1224-1229. https://doi.org/10.1161/STROKEAHA.110.609503

Flowers, H. L., Flamand-Roze, C., Denier, C., Roze, E., Silver, F. L., Rochon, E., ... \& Langdon, C. (2015). English adaptation, international harmonisation, and normative validation of the Language Screening Test (LAST). Aphasiology, 29(2), 214-236. https://doi.org/10.1080/02687038.2014.965058

Indonesia, P. P. N. (2016). Standar Intervensi Keperawatan Indonesia. Jakarta: PPNI.

Kemenkes, R. I. (2014). Situasi kesehatan jantung. Pusat Data Dan Informasi Kementerian Kesehatan RI.

Kertesz, A. (2007). Is there a need for standardized aphasia tests? Why, how, what and when to test aphasics. Journal Aphasiology. 313-317. https://doi.org/10.1080/02687038808248931

Koenig-Bruhin, M., Vanbellingen, T., Schumacher, R., Pflugshaupt, T., Annoni, J. M., Müri, R. M., ... \& Nyffeler, T. (2016). Screening for language disorders in stroke: German validation of the language screening test (LAST). Cerebrovascular diseases extra, 6(1), 27-31. https://doi.org/10.1159/000445778

Lumbantobing, S. M. (2000). Neurologi klinik pemeriksaan fisik dan mental. Jakarta: Balai Penerbit FK UL. 


\section{Journal Of Nursing Practice}

http://thejnp.org

ISSN: 2614-3488 (print); 2614-3496 (online)

Vol.3 No.2. April 2020. Page.210-219

Marshall, R. C., \& Campbell, S. (2013). Treatment of Aphasia In The Acute Care Setting : Getting Off on the Right Foot. Lexington: University of Kentucky.

Pinzon, R., \& Asanti, L. (2010). Awas stroke! pengertian, gejala, tindakan, perawatan dan pencegahan. Penerbit Andi.

Poslawsky, I. E., Schuurmans, M. J., Lindeman, E., \& Hafsteinsdóttir, T. B. (2010). A systematic review of nursing rehabilitation of stroke patients with aphasia. Journal of clinical nursing, 19(1-2), 17-32. https://doi.org/10.1111/j.13652702.2009.03023.x

Prins, R., \& Maas, W. (2002). Afasia Deskripsi Pemeriksaan Penanganan. Jakarta: Fakultas Kedokteran Universitas Indonesia.

Shehata, G. A., El Mistikawi, T., Al Sayed, K. R., \& Hassan, H. S. (2015). The effect of aphasia upon personality traits, depression and anxiety among stroke patients. Journal of affective disorders, 172, 312-314. https://doi.org/10.1016/j.jad.2014.10.027

Silbernagl, S., \& Lang, F. (2007). Teks \& atlas berwarna patofisiologi. Jakarta: EGC.

Suwardianto, H. (2018). Level Of Perception Emergency Skills In Youth Red Cross. Journal Of Nursing Practice, 2(1), 17-24. https://doi.org/10.30994/jnp.v2i1.38

Suwardianto, H., \& Rimawati, R. (2018). Explicit Instruction Model (EIM): Daily Training Emergencies Preparedness (DTEP) Toward Skills of Participants the Youth Red Cross. In The 2nd Joint International Conferences. 2(2). 403-410.

Suwardianto, H., Richard, S. D., Prasetyo, A., \& Utami, R. S. (2017). PHYSICAL FUNCTION-TARDIVE DYSKINESIA (PFTD) ON CRITICAL PATIENTS IN INTENSIVE CARE UNIT. Jurnal Ners, 12(2), 196-204. http://dx.doi.org/10.20473/jn.v12i2.4504

Venketasubramanian, N., Tan, L. C., Sahadevan, S., Chin, J. J., Krishnamoorthy, E. S., Hong, C. Y., \& Saw, S. M. (2005). Prevalence of stroke among Chinese, Malay, and Indian Singaporeans: a community-based tri-racial cross-sectional survey. Stroke, 36(3), 551-556. https://doi.org/10.1161/01.STR.0000155687.18818.13

Wang, W., Jiang, B., Sun, H., Ru, X., Sun, D., Wang, L., ... \& Chen, Z. (2017). Prevalence, incidence, and mortality of stroke in China: results from a nationwide population-based survey of 480687 adults. Circulation, 135(8), 759-771. https://doi.org/10.1161/CIRCULATIONAHA.116.025250

Weiner, H., \& Levitt, L. P. (2000). Buku saku neurologi. Jakarta. EGC.

Yusiana, M. A \& Suwardianto, H. (2014). The Effectiveness Of Deep Breathing and Slow Stroke Back Massage to Decrease The Blood Pressure On A Patient With Hypertension. Indonesian Nursing Journal of Education and Clinic (INJEC). 1(1). 31-39. http://dx.doi.org/10.24990/injec.v1i1.49 